\title{
Infertility: An Emerging Public Health Issue in Nepal
}

\author{
Madhav Gautam, ${ }^{1 *}$ Prabodh Risal ${ }^{2}$
}

Affiliations:

${ }^{1}$ Department Of Biochemistry

Kantipur Dental College, Kathmandu, Nepal

2.Department of Biochemistry

Kathmandu University School of Medical Sciences

Dhulikhel, Kavre, Nepal

Correspondence to:

Madhav Gautam

Department of Biochemistry

Kantipur Dental College, Kathmandu, Nepal

Email: drmadhavgautam@gmail.com

\section{How to cite this Article:}

Gautam M., Risal P. Infertility: An Emerging Public Health Issue in Nepal. Ann. Clin. Chem. Lab. Med.2017:3(1); 1-2

DOI: http://dx.doi.org/10.3126/acclm.v3i1.17717

(C) 2017 Nepalese Association for Clinical Chemistry

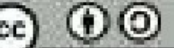

This work is licensed under a Creative Commons Attribution-Share Alike 4.0 International License.
Infertility is one of the major health problems worldwide, including Nepal. The average prevalence of infertility in developing countries is estimated to be around $6.9-9.3 \%{ }^{1}$. An increasing trend of infertility has been noticed recently in Nepal however, exact prevalence is still unknown.

Among the various male and female infertility factors, abnormal reproductive tract, quality of sperm and embryo, abnormalities in the implantation process and other conditions including immunological factors are common $^{2}$. Similarly, lifestyle factors of infertility are sedentary lifestyle, heavy use of alcohol, smoking, late marriage, miscarriages and frequent abortion ${ }^{3}$. Particularly in Nepal, millions of young fertile groups have migrated for job and they are coming back home after long gap and this may have reduced the fertility ${ }^{4}$. Some time, the migrant come to visit home and they might carry sexual transmitted diseases and this may have caused infertility ${ }^{5}$.

The heavy use of insecticide and pesticide in fruits and vegetables has been big news in Nepal, and its toxic and harmful effects have been highlighted in the local news-papers. The governments have initiated monitoring the use of organophosphate and carbamates in vegetables and fruits in Kalimati market, and have established the laboratory for immediate testing. The government have the plain to extend the monitoring system in other parts of the country like Kavre, Makwanpur , Dhading, Kaski, Rupendhai, and Banke districts. Apart from this, the government is planning for random monitoring of insecticides and pesticides in commercial vegetable 
growing areas. The heavy use of insecticide and pesticide in vegetable farming and consumption of insecticide and pesticide is one of the factors that results infertility in male and female $^{6}$. It causes decrease in the fertility index, which directly depends on weight of testes, sexual glands, sperm mortality, sperm count and testosterone hormone ${ }^{6}$. Sperm production and androgen synthesis is controlled by a complex feedback loop involving the testis, hypothalamus and pituitary glands. The pituitary controls the function of the testis by producing follicular stimulating hormone (FSH) and the luteinizing hormone (LH) stimulates androgen synthesis ${ }^{7}$, ${ }^{8}$. The effect of pesticides on male and female reproduction has extensively studied and the possible mechanism has been clearly described ${ }^{9}$. Therefore, possibilities of increasing infertility in several commercial vegetables growing district in Nepal could not be ruled out.

In conclusion, migration of fertile age group abroad for job, lifestyle change and increasing use of pesticides in the crops may have played important role in the increasing cases of infertility in Nepal. However, the exact prevalence and causes of infertility in Nepal is still unknown. Therefore it is very important to conduct nationwide study.

\section{REFERENCES}

1. International estimates of infertility prevalence and treatment-seeking: potential need and demand for infertility medical care. Boivin J, Bunting L, Collins JA, Nygren KG Hum Reprod. 2007 Jun; 22(6):1506 -12 .

2. Marc A. Fritz LS. Clinical gynecologic endocrinology and infertility. $8^{\text {th }}$ edition. 2011.

3. Lifestyle factors and reproductive health: taking control of your fertility. Rakesh Sharma, Kelly R Biedenharn, Jennifer M Fedor, and Ashok Agarwal Reprod Biol Endocrinol. 2013; 11: 66.

4. Study of Infertile Couples Attending a Teaching Hospital in Eastern Nepal. Subedi S, Lamichhane S, Chhetry M. JNMA J Nepal Med Assoc. 2016 Jul-Sep;55(203):22-25
5. Apari P, de Sousa JD, Müller V (2014) Why Sexually Transmitted Infections Tend to Cause Infertility: An Evolutionary Hypothesis. PLoS Pathog 10 (8): e1004111.

6. Pesticide exposure: the hormonal function of the female reproductive system disrupted? Reini W Bretveld, Chris MG Thomas, Paul TJ Scheepers,Gerhard A Zielhuis, Nel Roeleveld.

7. Niewoehner CB. Endocrine pathophysiology. 1st ed. Madison (CT): Fence Creek Publishing; 1998.

8. De Groot LJ. Endocrinology. 3rd ed. Philadelphia (PA): WB Saunders; 1995.

9. Bretveld R, Brouwers M, Ebisch I, Roeleveld N. Influence of pesticides on male fertility. Scand $\mathrm{J}$ Work Environ Health 2007;33(1):13-28. 